\title{
Fire Behaviour of Cellular Composite Floor Steel Beams with Different Web Opening Shapes
}

\author{
ALI NADJAI, EL HADI ALI NAILI, SANGHOON HAN, FARIS ALI, NATHAN GOODFELLOW, and \\ SENGKWAN CHOI \\ University of Ulster \\ School of Built Environment \\ Shore Road, Jordanstown, Co. Antrim, Belfast BT37 0QB, UK
}

\begin{abstract}
This paper describes an experimental study at ambient and elevated temperatures on the behaviour of fullscale composite floor cellular steel beams. A total of five specimens with different steel geometries were tested under different monotonic loading conditions at ambient and elevated temperatures. All beams were designed for a full shear connection between the steel beam and the concrete flange using shear studs. Two failure temperatures were observed in the fire tests indicated that beam with circular opening failed by web post buckling and beams with elongated openings failed by Vierendeel bending associated with the buckling of the web posts of the steel section. It can be concluded that cellular beams in fire cannot simply be estimated by applying temperature dependent reduction factors on stiffness, as given in codes. A finite element model is then established with both material and geometrical non-linearity using shell elements to compare the experimental results. The comparison between the finite element prediction and actual tests results are quite good in terms of failure modes, load deflection behaviour and ultimate loads.
\end{abstract}

KEYWORDS: cellular steel beams, fire tests, finite element method.

\section{INTRODUCTION}

Cellular beams (CBs) are currently being widely used in multi-storey buildings where, as well as reducing the total weight of the steelwork, they help decrease the depth of floors by accommodating pipes, conduits and ducting. They are also used in commercial and industrial buildings, warehouses, and portal frames. CBs produced by modern automated fabrication processes can be competitive for the construction of both floor and roof systems. Their widespread use as structural members has prompted several investigations into their structural behaviour. The openings in the web can be of various shapes such as rectangular, castellated, circular, and elongated as demonstrated in Fig. 1. CBs openings sizes can vary from $50 \%$ of the overall depth of the beam to $75 \%$ of the depth.

In the UK and Europe, in particular, the development of a wide variety of innovative composite floor systems has been notable. Investigation of the behaviour of composite beams with isolated web openings in otherwise solid webs has shown that the slab shear-carrying capacity significantly increases beyond that of the steel beam alone. This is due to the enhanced flexural and shear capacity of the upper part of the beam across an opening, although an unsupported web post is more susceptible to buckling. The structural behaviour of beams with openings is relatively complex and involves the main failure modes which are included in the design model for ULS design at ambient temperature and in fire conditions described in the literature review [1-4]. In fire, the temperature distribution across a composite member is non-uniform, since the web and bottom flange have thin cross-sections and a greater exposed perimeter than the top flange [5]. The deterioration of the material properties of the web will therefore have an important effect on the overall performance of the member in the event of fire.

This paper aims to present the experimental and numerical studies of cellular beams with circular and elongation opening at ambient and elevated temperatures which have the potential to provide essential data in several areas currently lacking systematic research. The target of this study comprehends the investigation and the performance under a standard heating regime, the failure mechanisms of cellular beams and temperature distribution through the specimens. 


\section{EXPERIMENTAL TEST PROGRAM}

The tests were carried out on five full-scale composite cellular steel beams using span lengths of $4500 \mathrm{~mm}$ subjected to one- and two-point loading and having different web opening shapes as demonstrated in Fig. 1. The geometry data of the beams tested are given in Table 1 .

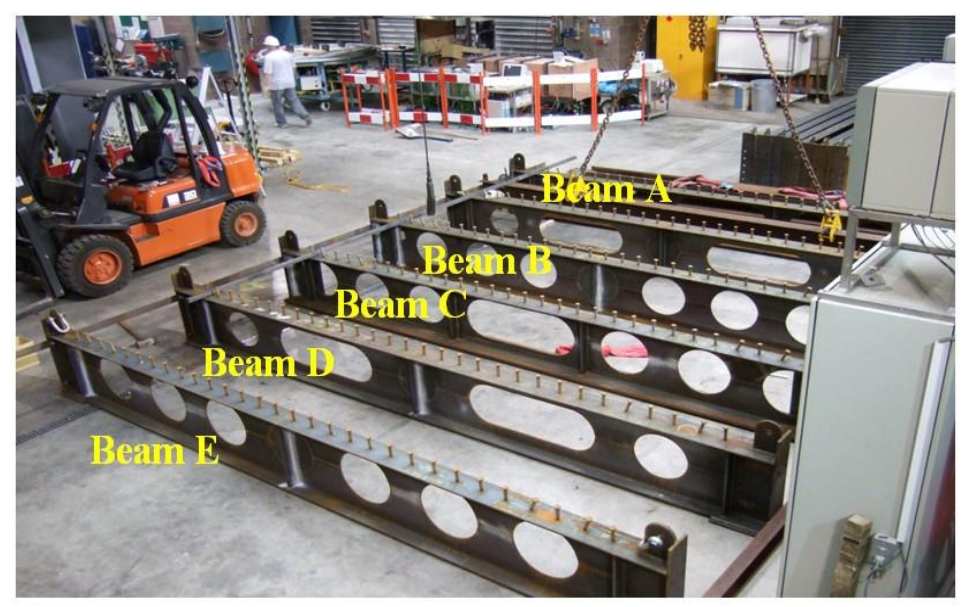

Fig. 1. Steel cellular beams with different opening shapes

Table 1. Geometry data.

\begin{tabular}{|l|c|c|c|c|c|}
\hline & Beam A & Beam B & Beam C & Beam D & Beam E \\
\hline Span (mm) & 4500 & 4500 & 4500 & 4500 & 4500 \\
\hline Top flange-w/t (mm) & $141.8 / 8.6$ & $141.8 / 8.6$ & $172.2 / 13.0$ & $190.4 / 14.5$ & $172.2 / 13.0$ \\
\hline Top tee depth (mm) & 287.4 & 302.1 & 255 & 275 & 255 \\
\hline Bottom flange-w/t (mm) & $141.8 / 8.6$ & $152.4 / 10.9$ & $307.1 / 23.6$ & $190.4 / 14.5$ & $190.4 / 14.5$ \\
\hline Bottom tee depth (mm) & 287.4 & 328 & 300 & 275 & 300 \\
\hline Web thickness-top/btm (mm) & $6.4 / 6.4$ & $6.4 / 7.6$ & $8.1 / 14.1$ & $9.0 / 9.0$ & $8.1 / 9.0$ \\
\hline Overall depth (mm) & 575 & 630 & 555 & 550 & 555 \\
\hline Number of circular cells & 8 & 6 & 6 & 2 & 6 \\
\hline Number of elongated cells & 0 & 0 & 1 & 2 & 0 \\
\hline Number of cells with infill & 0 & 0 & 0 & 1 & 1 \\
\hline No. of cells with semi infill & 0 & 0 & 2 & 0 & 0 \\
\hline Overall number of cells & 8 & 6 & 7 & 5 & 7 \\
\hline Cell diameter (mm) & 375 & 450 & 375 & 335 & 375 \\
\hline Cell spacing (mm) & 500 & 630 & 600 & 600 & 600 \\
\hline
\end{tabular}

The concrete slabs were all nominally $150 \mathrm{~mm}$ thick and $1200 \mathrm{~mm}$ wide using normal-weight concrete $\left(\right.$ Grade $35 \mathrm{~N} / \mathrm{mm}^{2}$ ). The slab reinforcement consisted of welded wire mesh reinforcement A142 having yield strength of $460 \mathrm{~N} / \mathrm{mm}^{2}$. Full interaction between the slab and the beam was ensured in all specimens by the use of a high density of shear connectors of $19 \mathrm{~mm}$ diameter studs at height $120 \mathrm{~mm}$. The shear studs have been equally distributed in one row with a spacing of $150 \mathrm{~mm}$ over the beam length. A Holorib sheets HR 51/150 with a thickness of $1.25 \mathrm{~mm}$ have been used as sheeting. The measured yield stress from a tensile yield stress from a tensile test was $F_{y}=327 \mathrm{~N} / \mathrm{mm}^{2}$. Concrete compressive strength was determined at different stages of time: after 2 weeks, 28 days and during the testing days giving an average of $35 \mathrm{~N} / \mathrm{mm}^{2}$ using a compressive strength calibrated machine at the University of Ulster.

Figure 2 demonstrates stress block for CB section. The properties of composite beams can be calculated with these dimensions and material's strength. 


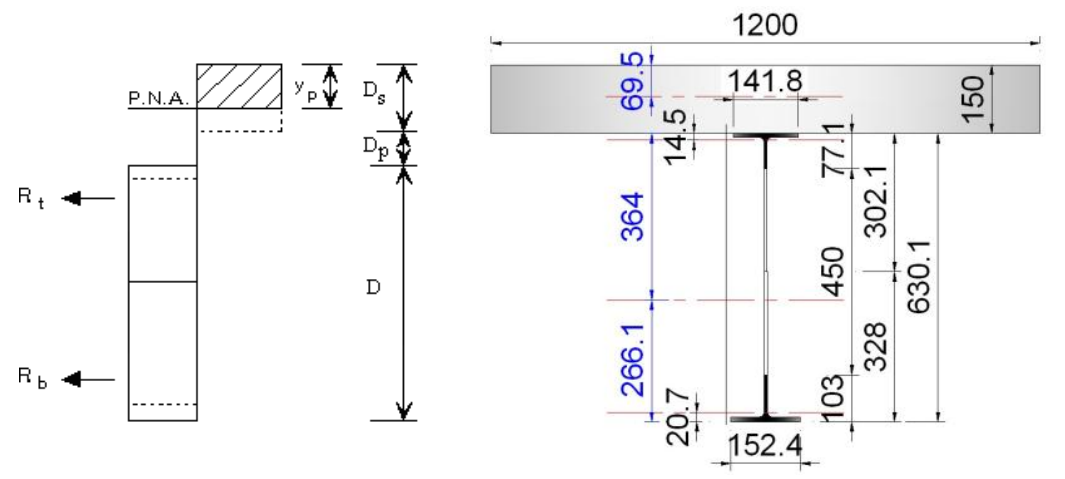

Fig. 2. Internal force diagram of composite $\mathrm{CB}$ section and section of Beam B.

The moment of inertia of steel $\mathrm{CB}$ is as follows:

$I_{C B}=\left(I_{T T}+A_{T T} \cdot e_{1}^{2}\right)+\left(I_{B T}+A_{B T} \cdot e_{2}^{2}\right)$

where, subscripts $T T$ and $B T$ are a top tee and bottom tee; $e_{1}$ and $e_{2}$ are distance between centroid of $\mathrm{CB}$ and top/bottom tee.

Taking moment about the centroid of the effective slab depth gives [10];

$M_{p l, R d}=R_{s}\left(y_{C B}+D_{p}+D_{s}+y_{p} / 2\right)$

where, $y_{C B}$ is the distance from PNA to the CB centroid.

The moment capacity of the composite section can be defined by the linear interaction equation with respect to the degree of shear connection $K$, in where would be considered full connection.

$M_{C}=M_{S}+K\left(M_{P C}-M_{S}\right)$

where, $M_{S}$ is the plastic moment capacity of the steel beam; $M_{P C}$ is the plastic moment capacity based on full shear connection.

Based on this calculation, the plastic moment capacity of Beam A and B were $479.2 \mathrm{kNm}$ and $629.8 \mathrm{kNm}$ which give applied loads of $547 \mathrm{kN}$ and $559 \mathrm{kN}$ respectively.

\section{TESTING PROCEDURE OF THE AMBIENT TESTS}

Both Tests A and B were conducted using portal frames with a capacity of $160 \mathrm{t}$ loading system. The composite beam specimen was simply supported at both ends. A $600 \mathrm{kN}$ hydraulic jack was used to apply the monotonic load. The load was applied to the top concrete flange through a distribution beams exhibited in Fig. 3 for two point loadings.

For both Test A and B load cycles at a load level of $20 \%$ and $60 \%$ of the pre-design load have been applied to avoid slippage of the load introduction and supports as well as friction in the shear joint and the structure. All the load cells used for the experiment were calibrated before the testing procedure took place.

Twenty percent of the pre-design load used by Westok software has been kept for one-hour time before load has been increased. Each load step with a value of $10 \mathrm{kN} / \mathrm{step}$ was kept for $3 \mathrm{~min}$ intervals.

Both ultimate failures of the specimens were associated with web post buckling, and study of various measures of buckling load led to the conclusion that this maximum load represented the web buckling load. Variation of central deflection with load is shown in Fig. 4. In each case the buckling mode comprised double curvature bending of the post (see Fig. 4). Before this occurred, high strains had developed 
following tensile yield of the lower part of the steel beam. Tensile strains developed above the opening indicating that the neutral axis was close to or in the slab.
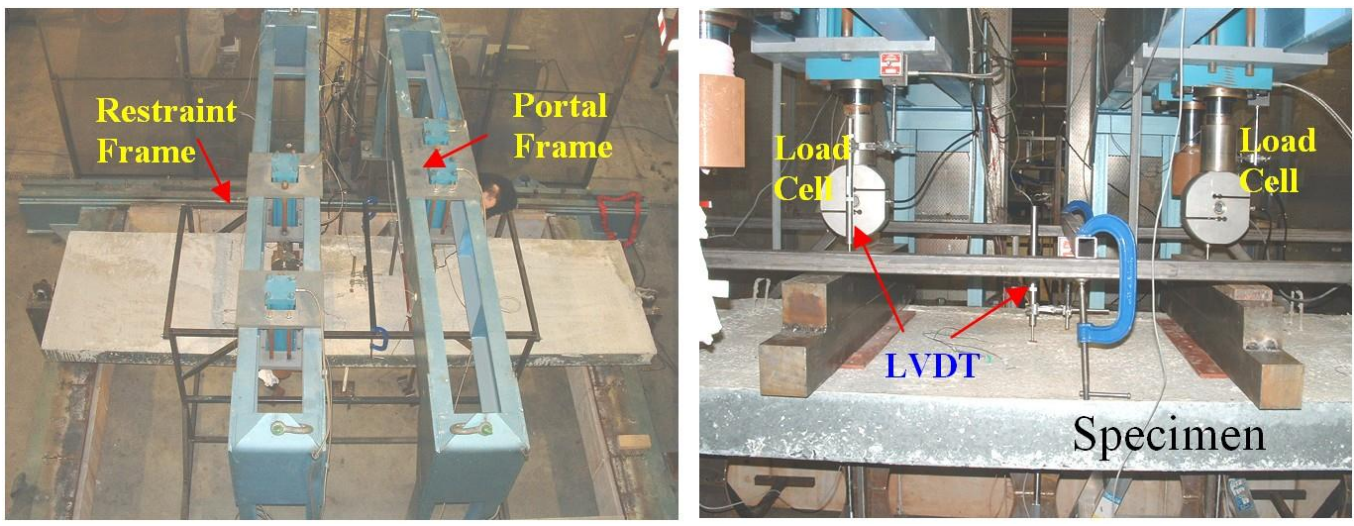

Fig. 3. Experimental set-up and load introduction of Test B.

After the post web buckling took place the beam was then followed by hinges forming around the openings making the webs buckle in the form of an S shape. BS 5950: Part 1 specifies that the maximum deflection under factored load for a beam of this type should not exceed: span/200. The maximum deflection in both test beams just before failure was $10 \mathrm{~mm}$, which is well within British Standard recommendations. Diagrams of the measurements as well as photographs of the failure mechanism are given in the following figures.
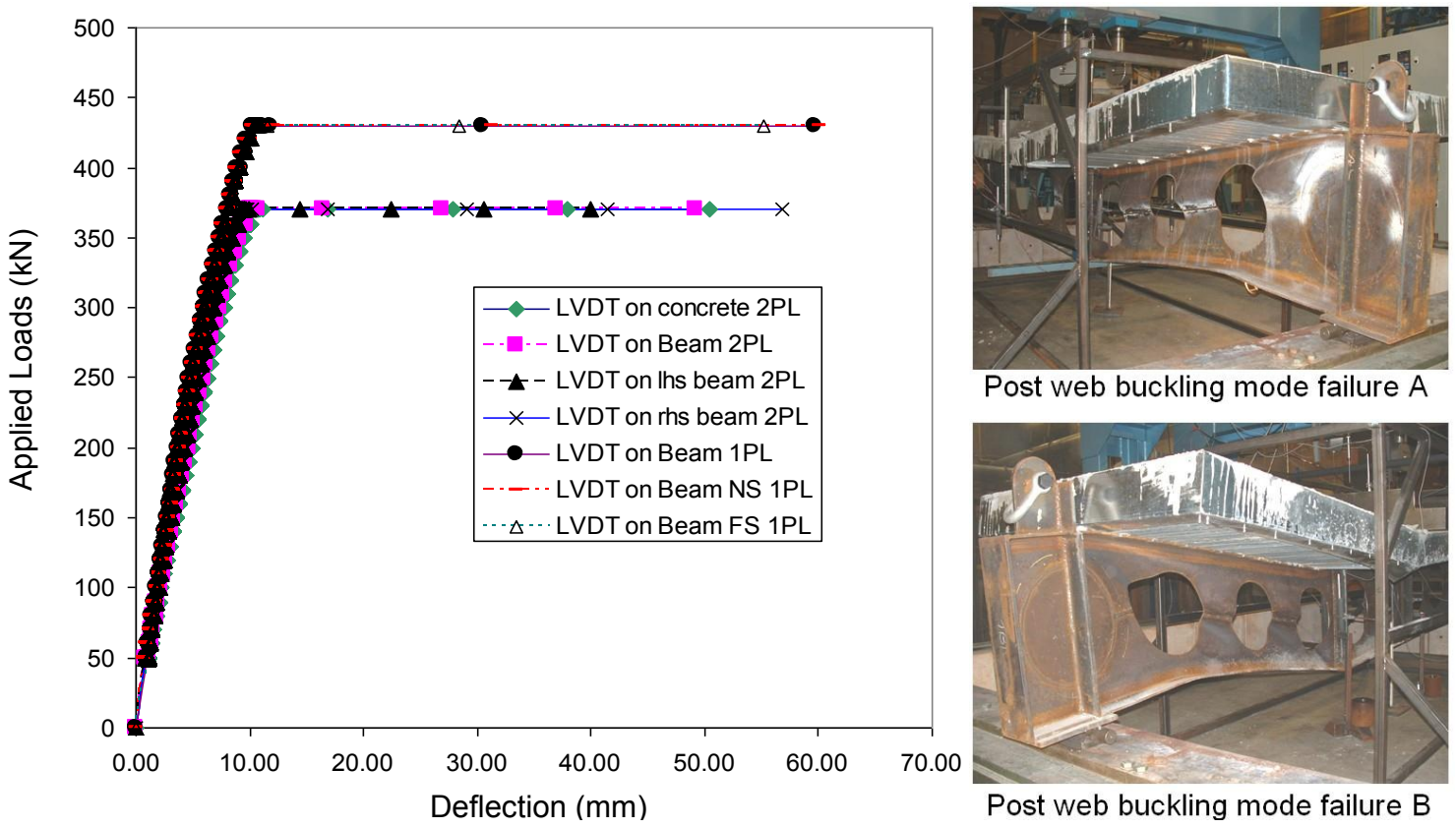

Post web buckling mode failure $A$

Fig. 4. Load vs. deflection for Tests A and B at ambient temperature.

\section{INITIAL STUDIES AT AMBIENT TEMPERATURE}

The composite cellular steel beams in ambient and fire tests were modelled using the commercial finite element software DIANA at the University of Ulster. Shell elements with the ability to handle large strains, large deformations, and plasticity were used to model the cellular steel beam. Composite brick elements were used, incorporating a smeared crack approach for the concrete, to model the composite slab. Both the steel deck, as a bottom layer, and the reinforcing mesh as a layer within the concrete was included within 
the composite shell element. Due to the high density of the shear connectors used in the tests, full interaction between the beam and supporting composite slab was assumed. This assumption is also justified from test observations [8] which confirmed that no stud failure occurred before web post buckling of the beam.

Imperfections were introduced, based on an Eigen value buckling analysis, with the amplitude of the imperfections being governed by the thickness of the steel plate for local bucking and the overall length of the section for global buckling [9]. An implicit analysis was conducted in two steps, where the load was applied in the first step and the temperature was applied in the second step.

Figure 5 shows the load deflections curves compared between analytical and experimental results and the output deformed shape of the DIANA program. It is obvious when comparing the two that the same failure mode has occurred as the web post buckles under the applied load forming an S-shape caused by the formation of hinges around the openings.

Exactly the same calibrated model was used to simulate the cold tests for Beams C, D and E in order to have the ultimate failure loads before conducting its fire resistance tests [6-7]. And the failure loads obtained by DIANA were $470 \mathrm{kN}$ (Beam C), $470 \mathrm{kN}$ (Beam D) and $700 \mathrm{kN}$ (Beam E) respectively.
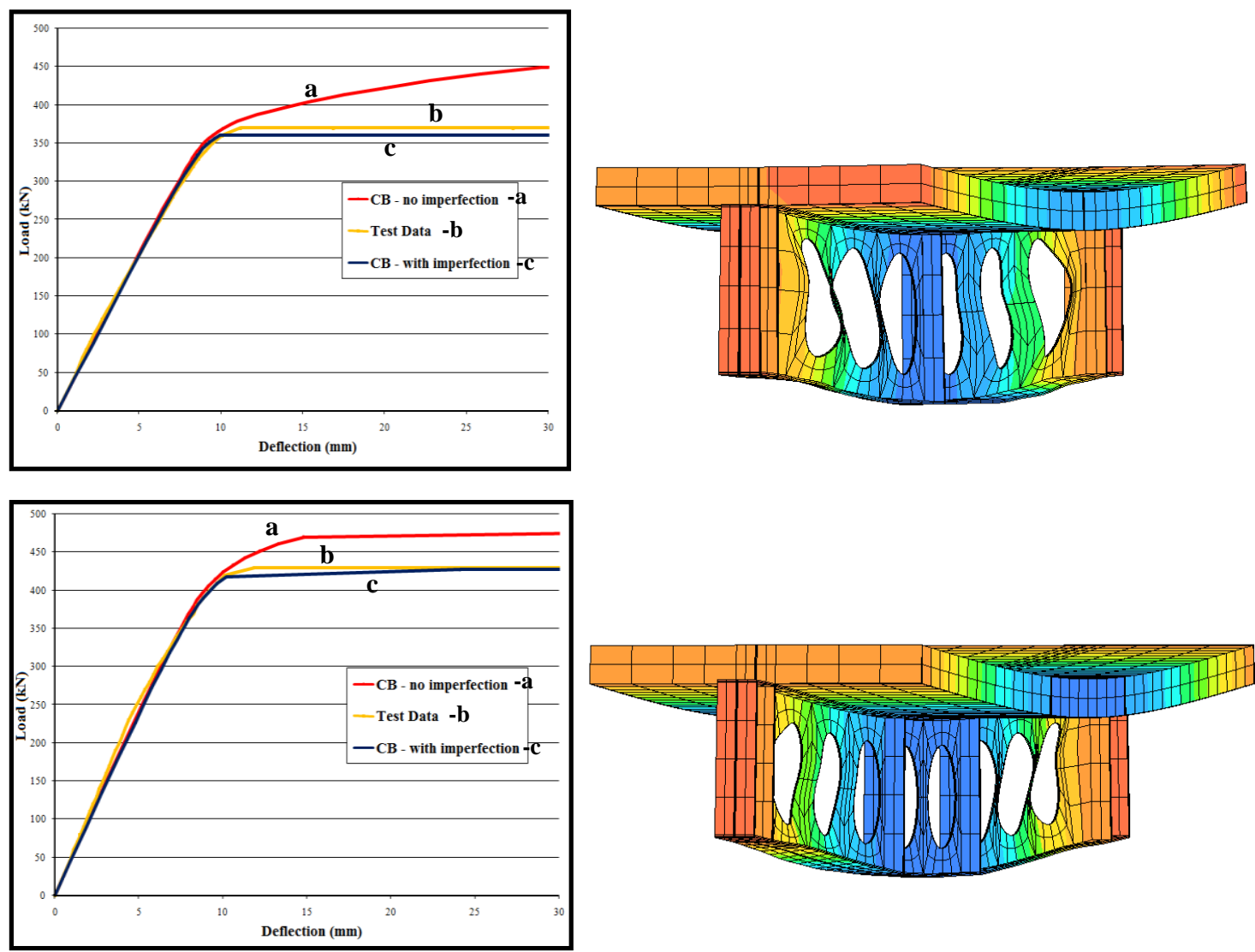

Fig. 5. Load deflection results compared with experimental tests and its deformed mesh.

\section{TEST RESULTS AT ELEVATED TEMPERATURES}

The applied loads for Tests C, D and E are calculated as $140 \mathrm{kN}, 140 \mathrm{kN}$ and $210 \mathrm{kN}$ respectively from 0.3 $x$ failure load obtained from the analytical cold tests. All beams were kept loaded to their respective applied load for duration over an hour time before the furnace started functioning. The positions of the thermocouples (Fig. 6) were located at each web post along its depth of the section, around the openings and also trough the slab cross-sections. The three fire tests were carried out under the ISO834 fire curve. Only the lower side of the slab and the steel section were fire-exposed. 


\section{Temperature Distribution and Deflection}

The maximum temperature values were recorded in the web, reaching up to $795^{\circ} \mathrm{C}$ in Test $\mathrm{D}$ after $39 \mathrm{~min}$ (Fig. 7). The beam responds linearly due to the severe rise in temperature until about $15 \mathrm{~min}$ by which time the furnace temperature has risen to over $730^{\circ} \mathrm{C}$. After this point the beam rate of deflection begins to gradually increase due to the deterioration of the beam properties until about 24 min when the beam deflection is recorded at furnace temperature around $800^{\circ} \mathrm{C}$. Between 20 and 25 min time, Beam D rate of deflection starts to increase rapidly until the point of failure at 39 min by which time the beam have deflected by $249 \mathrm{~mm}$ at furnace temperature around $870^{\circ} \mathrm{C}$. In the case of the ISO834 fire, there is no time for significant heat to be conducted through the concrete slab so there is less of a restraining force generated and the deflection rises rapidly. It can be deduced from this that the main reason for failure occurring is due to the loss of the steel strength and stiffness rather than a combined loss of material property in the steel and concrete. Figure 7 shows the results of the fire Test C, D and E.

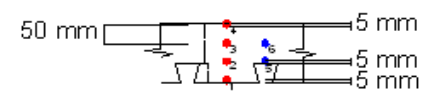

A
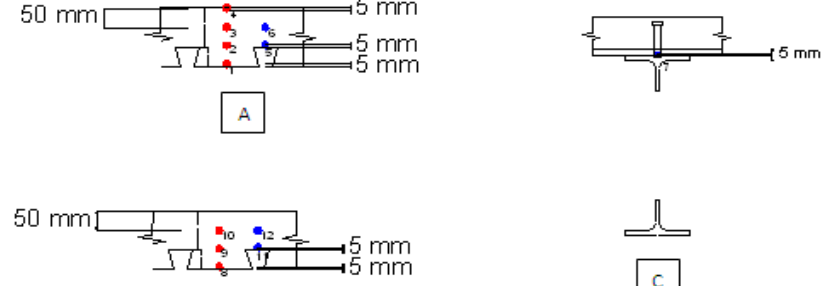

$B$

Openings $1 / 2$ and $6 / 7$

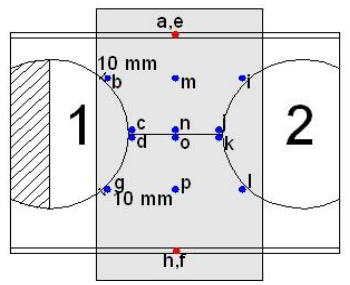

Zone 1: 16 Thermocouples Zone 7: 16 Thermocouples
Openings $2 / 3,5 / 6$

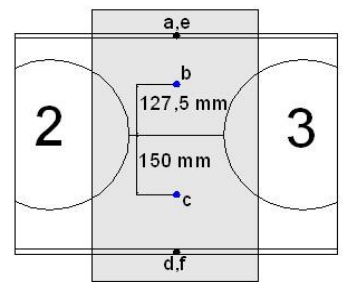

Zone 2: 6 Thermocouples Zone 6: 6 Thermocouples

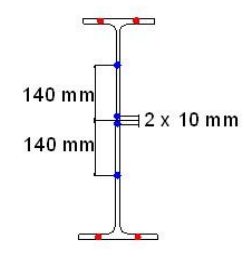

S1

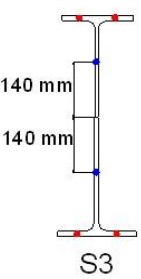

S3

Zone 3: 8 Thermocouples

Zone 4: 6 Thermocouples

Zone 5: 8 Thermocouples

Openings 3 to 5

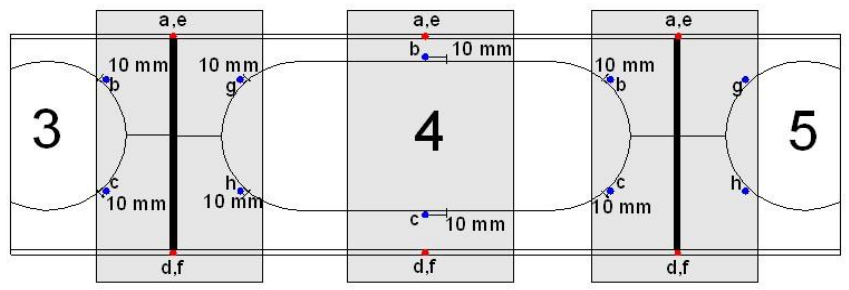

Fig. 6. Typical thermocouple positions in cellular tested beams and concrete slab cross-sections. 

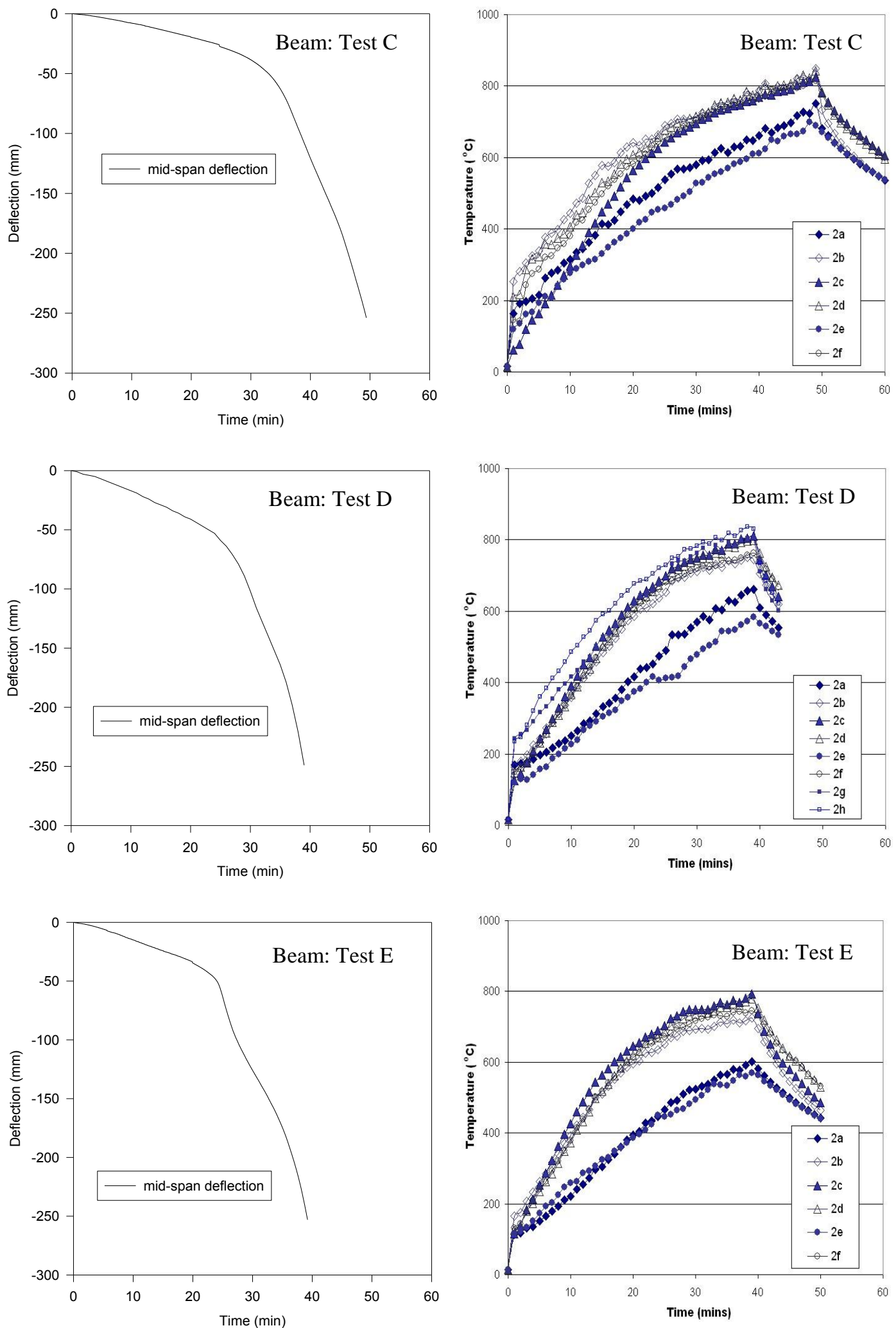


\section{Failure Mechanisms}

The temperature difference between the top and bottom flange is observed to be greater due to the significant rise in furnace temperature in the case of the ISO fire, but it is not relevant for the web post buckling. However, buckling of the web posts begins to occur before the final point of failure as the steel beam temperatures are in excess of $600{ }^{\circ} \mathrm{C}$ at which point the steel has less than half of its design strength and Young's modulus is reduced to $20 \%$. When the furnace temperature is around $750{ }^{\circ} \mathrm{C}$, the Young's modulus decreases quicker than the steel strength limit which causes the failure modes. The main failure mode in Test $\mathrm{C}$ and Test $\mathrm{D}$ was the Vierendeel bending associated with the buckling of the web posts of the steel section. The web post buckling was the main failure mode in the Test $\mathrm{E}$.
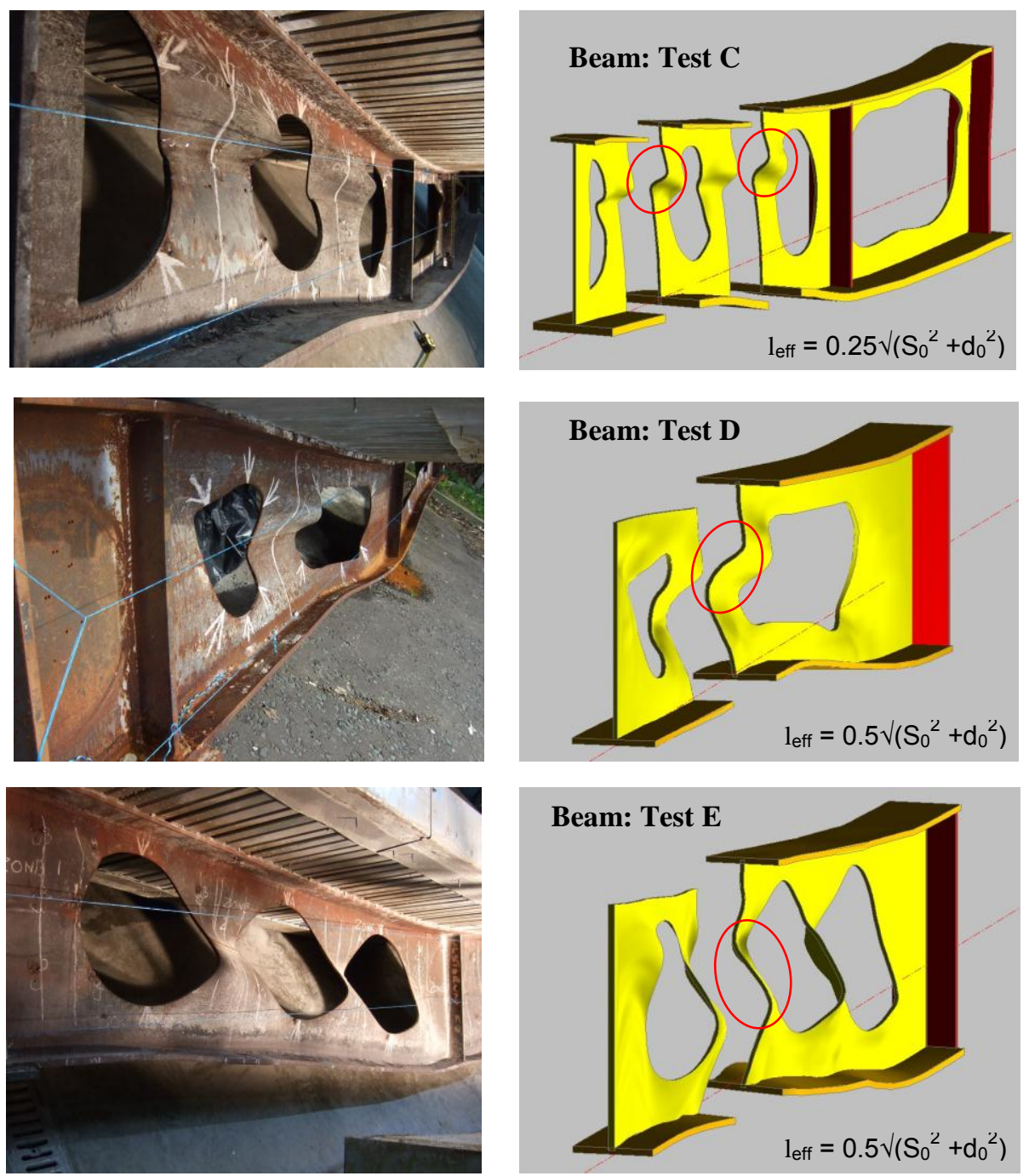

Fig. 8. Failure mechanism for the beams tested in fire conditions.

From Fig. 8, we can see that the effective length subjected to buckling is different from beam-to-beam and therefore the shear buckling capacity of the web post at temperature $\theta$, expressed in terms of longitudinal shear needs to be adjusted in comparison with the SCI approach design [2].

The effective length, $l_{\text {eff }}$, as an equivalent web post strut for a symmetrical section is given by [4] 


$$
l_{e f f}=0.5 \sqrt{\left(S_{0}^{2}+d_{0}^{2}\right)}
$$

This value can be used for calculating the slenderness of the web post at the elevated temperatures (see Fig. 9). But in the asymmetric section where critical web thickness is nearly half of the other, effective length, shown as Test $\mathrm{C}$, considered to be applied by

$$
l_{\text {eff }}=0.25 \sqrt{\left(S_{0}^{2}+d_{0}^{2}\right)}
$$

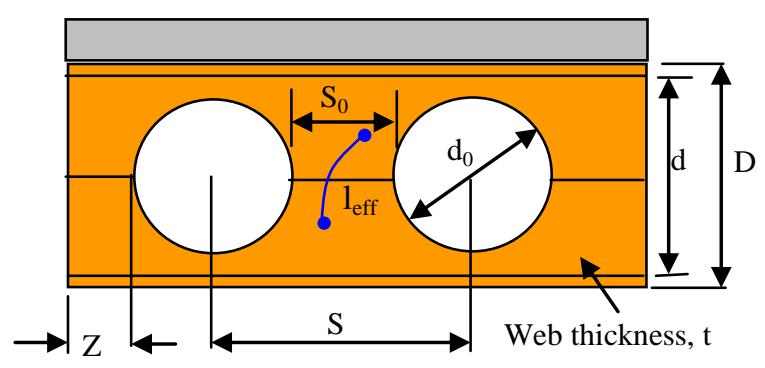

Fig. 9. Detail information of cellular beams.

\section{Analytical Model}

The bending moment capacity of the beam in both the fire and ultimate limit states can be limited by the horizontal shear capacity and/or the buckling capacity of the web posts, as this limits the axial force that can be generated in the bottom tee (see Fig. 10).

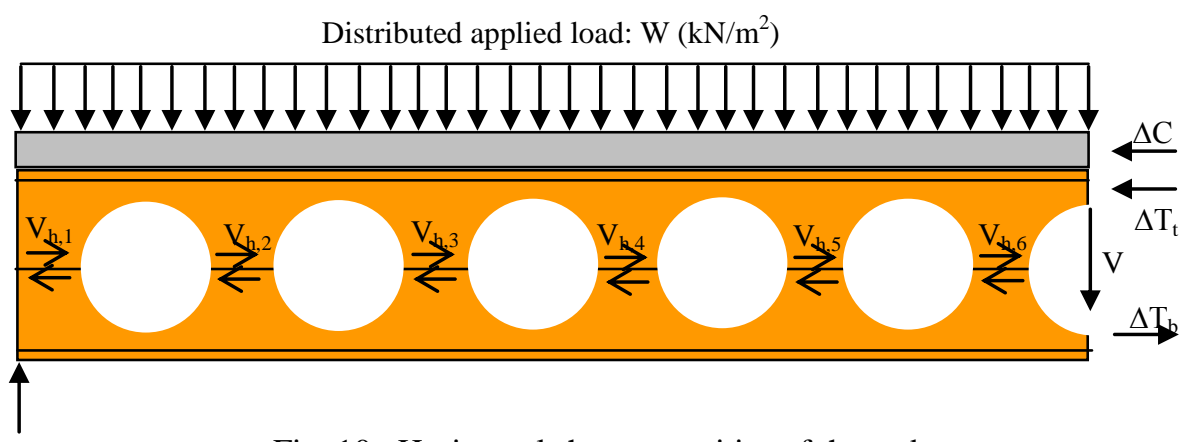

Fig. 10. Horizontal shear capacities of the web.

The force in the bottom tee at the maximum moment position, $T_{b}$, cannot exceed the sum of the horizontal shear capacities of the web posts, $V_{h, i}$.

$\sum V_{h, i} \geq T_{b, \theta}$

where $T_{b . \theta}$ is the plastic tensile capacity of the bottom tee at temperature $\theta . V_{h, i}$ is the lesser of the horizontal shear capacity and the buckling capacity of $i^{\text {th }}$ web post.

$V_{h, \text { buck }, \theta}=\frac{\chi \cdot f_{\mathrm{y}, \theta} \cdot S_{0} \cdot t_{w, \text { criical }}}{\gamma_{\mathrm{m}}}$ 


$$
\phi=0.5\left(1+\alpha\left(\lambda_{\theta}-0.2\right)+\lambda_{\theta}^{2}\right)
$$

$$
\chi=\frac{1}{\phi+\sqrt{\left(\phi^{2}-\lambda_{\theta}^{2}\right)}} \text { and } \lambda_{\theta}=\sqrt{\frac{f_{y, \theta}}{f_{E, \theta}}}
$$

In here, $f_{y, \theta}$ is the design yield strength of steel at temperature $\theta$. It is recommended that the $\lambda_{\theta}$ needs a proper adjustment in order to approach the practicality of the different cellular beams used in design constructions.

$$
f_{E, \theta}=\frac{\pi^{2} E_{\theta}}{\lambda^{2}} \text { and } \lambda=\frac{\sqrt{12} l_{e f f}}{t_{w, c r i t i c a l}}
$$

where, $f_{E, \theta}$ is the elastic buckling stress at temperature $\theta$ and $\lambda$ is the slenderness, determined on the basis of an effective length of an equivalent web post strut $l_{e f f .} t_{w, \text { critical }}$ is the thickness of the web, in which,

$$
\begin{array}{llll}
l_{\text {eff }}=0.5 \sqrt{\left(S_{0}{ }^{2}+d_{0}^{2}\right)} & \text { for } & t_{w /} / t_{w b}=1.0 & \text { for circular and elongated symmetric section } \\
l_{\text {eff }}=0.25 \sqrt{\left(S_{0}^{2}+d_{0}^{2}\right)} \quad \text { for } & t_{w /} / t_{w b} \leq 0.6 & \text { for circular and elongated asymmetric section }
\end{array}
$$

\section{FINITE ELEMENT MODEL FOR FIRE CONDITIONS}

The steel beam sections and slab were modelled as the concrete section in the ambient temperature models using the solid-brick element and heating element in order to add a temperature dependent mesh over the top of the structural mesh. In order to simulate the tests as accurately as possible the beams were split into different areas. Different time/temperature curves were introduced to the model according to the average thermocouple reading recorded in the tests for the bottom flange, bottom web, upper web, upper flange, bottom layer of steel decking and concrete slab.

The failure mode that has taken place in the cellular Beam D is due to the Vierendeel bending associated with web posts buckling as was seen in the fire test and in the ambient temperature conditions. Figure 11 illustrates a comparison between the experimental test and the existing commercial software (DIANA). The first approach of the numerical modelling seems not to agree well with the experimental fire test in comparison with the failure load. However, a proper calibration of the model is under development to predict better response with the experimental fire test. 


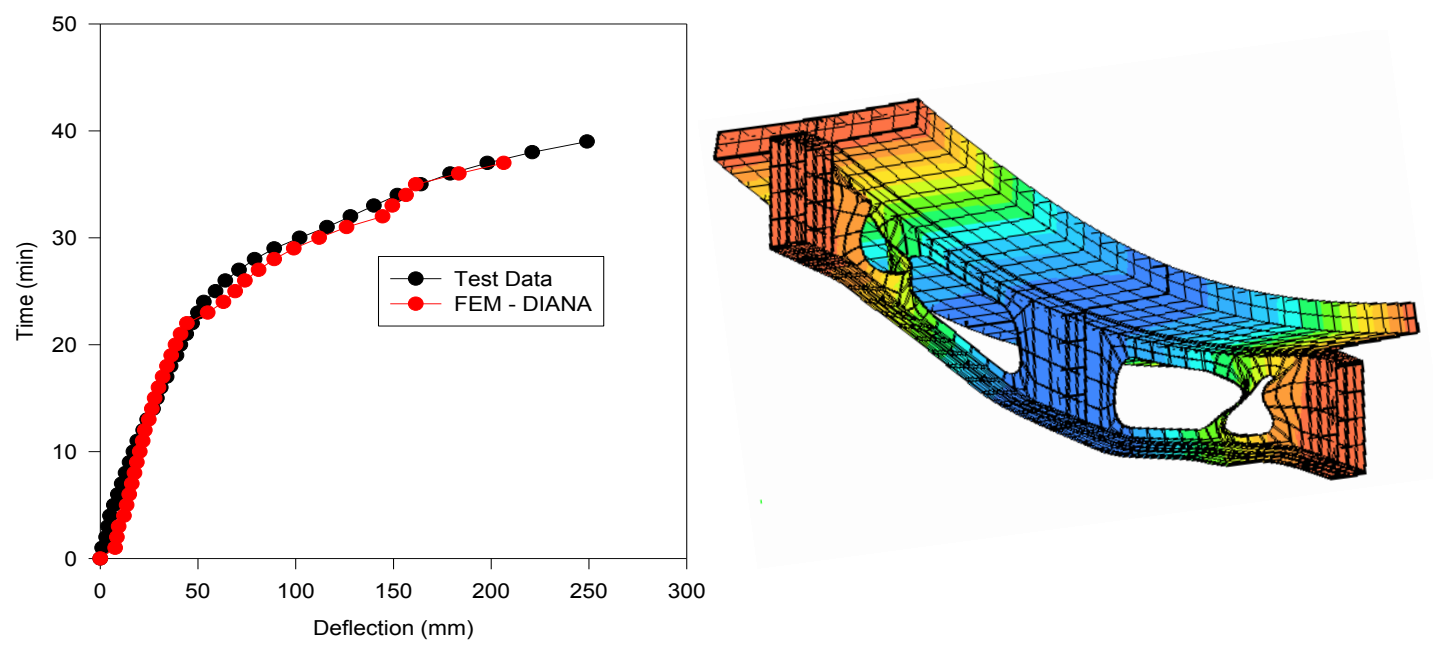

Fig. 11. Comparison of the finite element model and the test results of Beam D.

Because these two buckling modes occurred almost simultaneously, it was difficult to determine visually the dominant failure mode. However, with the analytical specimens it is possible to determine the interaction between the two buckling modes and to differentiate which region precipitated the beam's failure. The stress concentration in the bottom part (point B) of the web (Fig. 12) around the elongated opening near the circular opening is in tension to a greater extent than the other parts of the web around openings (point A). The failure mode of this beam test is clearly a Vierendeel mechanism as expected associated with web post buckling.
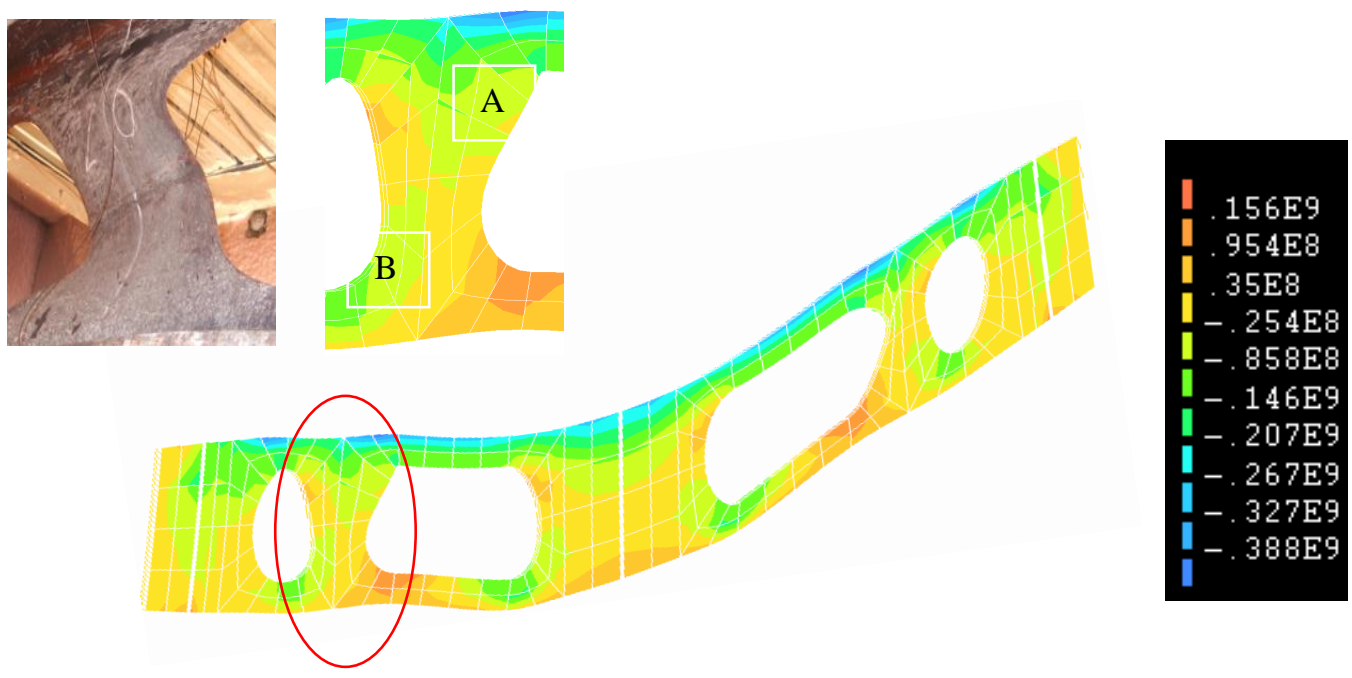

Fig. 12. Axial stress distribution in elements $\left(\mathrm{N} / \mathrm{m}^{2}\right)$.

\section{CONCLUSION}

This paper describes an experimental and analytical study of the behaviour of composite floor cellular steel beams in fire conditions having different opening shapes conducted at the FireSERT, University of Ulster. The study suggests the following:

- $\quad$ Beam $\mathrm{E}$ and $\mathrm{C}$ failed due to web post buckling and the instability resulted in sudden loss of stiffness and strength in the beams.

- $\quad$ Beam D failed by Vierendeel mechanism associated with web post buckling. 
- The experimental data has compared well with the results from the finite element modelling, giving confidence that it can be used for further parametric studies.

- The numerical model is capable to simulate the mechanical behaviour of composite cellular beam sections in both cold and at elevated temperature conditions with a relatively high accuracy.

- Adjustment of some equations listed in the SCI document in order to predict accurate post web buckling lengths for cellular beams with different shapes and cross sectional dimensions are proposed.

- Further protected cellular beams are in the plan to be tested in University of Ulster in order to permit the fire protection material to be evaluated over the range of deflections.

\section{ACKNOWLEDGEMENT}

The authors thank Mr Sam Kelly for the composite decking and Kingspan Ltd, Ireland.

\section{REFERENCES}

[1] Liu, T. and Liew, K., "Behaviour of cellular steel beam in fire," Interflam 2004, Interscience Communications Ltd, 2004, pp. 157-168.

[2] SCI, "Fire design of cellular beams with slender web posts," RT1006 V.02, Ascot, 2004.

[3] Bitar, D., Demarco, T. and Martin, P., "Steel and non composite cellular beams - novel approach for design based on experimental studies and numerical investigations," $4^{\text {th }}$ Eurosteel Conference, 2005.

[4] Lawson, R.M., Lim, J., Hicks, S.J. and Simms, W.I., (2006) Design of composite asymmetric cellular beams and beams with large web openings, Journal of Constructional Steel Research 62(6): 614-629. http://dx.doi.org/10.1016/j.jcsr.2005.09.012

[5] BS5950-8, "Structural use of steelwork in building - Part 8 : Code of practice for fire resistant design," 2003.

[6] Nadjai, A., Vassart, O., Ali, F., Talamona, D., Allam, A. and Hawes, M., (2007) Performance of cellular composite floor beams at elevated temperatures, Fire Safety Journal 42(6-7): 489-497, http://dx.doi.org/10.1016/j.firesaf.2007.05.001

[7] Nadjai, A., Goodfellow, N., Talamona, D., Ali, F., Bailey, C.G. and Siamak, B.M., "Experimental and numerical investigation on composite floor cellular steel beams in fire," $3^{\text {rd }}$ International Conference on Steel and Composite Structures (ICSCS07), International Conference on Steel \& Composite Structures, 2007, pp. 673-679.

[8] Nadjai, A., "Performance of cellular composite floor beams at ambient temperatures," FireSERT Test report, University of Ulster, 2005.

[9] Schafer, B.W. and Pekoz, T., (1998) Computational modeling of cold-formed steel: characterizing geometric imperfections and residual stresses, Journal of Constructional Steel Research 47(3): 193-210, http://dx.doi.org/10.1016/S0143-974X(98)00007-8

[10] SCI, "Design of composite and non-composite cellular beams," 100 p., 1994. 